\title{
The effects of perceived ease of use, usefulness, enjoyment and intention to use online platforms on behavioral intention in online movie watching during the pandemic era
}

\author{
Ribut Basuki $^{a}$, Zeplin Jiwa Husada Tarigan ${ }^{\text {b* }}$, Hotlan Siagian ${ }^{b}$, Liem Satya Limanta ${ }^{a}$, Dwi Se- \\ tiawan'a and Jenny Mochtara
}

${ }^{a}$ Faculty of Language and Literature, Petra Christian University, Surabaya, Indonesia

${ }^{b}$ Faculty of Business and Economics, Petra Christian University, Surabaya, Indonesia

\section{CH R O N I C L E}

Article history:

Received: June 18, 202

Received in revised format: June

29,2021

Accepted: September 6, 2021

Available online: September 9, 2021

Keywords:

Perceived ease of use

Perceived usefulness

Perceived enjoyment

Intention to use

Behavioral intention

\section{A B S T R A C T}

\begin{abstract}
Pandemic Covid-19 has resulted in disruption in various industry and business sectors. People spend more time at home than they do outside. People who like movies during this time can enjoy the cinema. However, during the covid-19 pandemic, it must be done online to follow strictly regulated restrictions on community activities to avoid the uncontrolled spread of the virus. As a result, streaming platforms with the advancement of internet technology are increasingly playing a role in providing online services for movie fans. This study investigated the effects of perceived ease of use, usefulness, enjoyment, and intention to use online platforms on behavioral intention in online movies during the Covid 19 pandemic. The questionnaires were distributed by sending google form links to respondents who have a streaming platform subscription in Indonesia. As many as 772 questionnaires were filled out completely and could be processed. Data analysis was done by using partial least squares with Smart PLS software. The results have shown that eight proposed hypotheses have been supported in this study. Perceived ease of use positively affects the perceived usefulness, perceived enjoyment, and intention to watch movies online. Furthermore, perceived usefulness affects perceived enjoyment and intention to watch movies online. Perceived enjoyment influences intention to use and behavioral intention. Finally, intention to use online platforms influences behavioral intention. This research contributes in theory to the technology acceptance model and provides film industry practitioners with insight into enhancing customer behavioral intention in the pandemic era.
\end{abstract}

(C) 2022 by the authors; licensee Growing Science, Canada.

\section{Introduction}

The initial coronavirus was discovered in the Chinese city of Wuhan in December 2019. Coronavirus attacks the respiratory system which is acute, severe, and very dangerous for human health (Verity et al., 2020). The virus spreads between a person and others through sparks that come out through coughing, discussing, or exhaling something (Zhang, 2020). The spark released by someone will touch the surrounding locations so that it is contaminated and endangers those around. Therefore, anticipating the spread of the virus can be done by keeping a distance between one person and the others. The consequences of restrictions impact the sustainability of the business, education, and life, making drastic changes in the economic, social, and cultural order (Ozili, 2020). The spread of the virus causes increased anxiety for both infected and uninfected people because the number of people who die from this covid increases continuously. A research conducted by Ghosh (2020) states that the concerns caused by covid resulted in the Indian government having to take swift action to stringent lockdown. However, the decision fatally affected the economy, forcing millions of poor people to starve and resulting in distance arrangements that could not be controlled.

* Corresponding author.

E-mail address: zeplin@petra.ac.id (Z. J. H. Tarigan)

(C) 2022 by the authors; licensee Growing Science, Canada. doi: $10.5267 /$ j.ijdns. 2021.9 .003 
Coronavirus caused panic in the community, especially the food availability needed during the quarantine process carried out by local government policies. This condition has an impact on the disruption of the balance between supply and food needs. The provincial government sets the availability of primary materials to maintain food security (Yu et al., 2020). Coronavirus also gives social problems to a country in providing jobs for people who cannot work due to business inability to survive in the pandemic conditions. The local government must find a solution to overcome it by conducting an online labor recruitment process. The Government in China provides employment consultations for college graduates and online employment consultations for disruptive communities. Serving the job seekers, the government provided consultations, and online interviews can be conducted online (Zhang, 2020). Coronavirus also determines changes in behavior for the world of tourism and hospitality, such as drastic changes in the tourism industry in terms of travel plans, travel, and preferences chosen by tourists (Wen et al. 2020). The covid pandemic also impacts the field of sports in North America, especially on American leagues. Running a business/sports business is constrained by the availability of finance because the main revenue comes from the audience in running the league so far. The government's policy of not permitting large crowds, and the necessity of keeping a distance, had an impact on the cancellation of all sports league activities. The loss of league clubs in America is estimated at 6.8 billion dollars if they do not get funds from ticket sales to spectators. The cancellation of this activity impacts the financial condition of sports clubs in the country so that solutions are made to overcome it by doing sports activities broadcast online and without spectators directly on the sports field (Ehrlich et al., 2020). The coronavirus outbreak in China resulted in an economic contraction in the African countries resulting in economic decline and people's inability to get basic needs and essential health and impact the management of health and education (Ozili, 2020). The worst social impact in Africa is restricting people's movements to suppress the spread of the coronavirus. Restrictions are to close schools, close universities, encourage people to stay at home and impact economic activity in the African country.

The covid pandemic also affects the entertainment industry, especially for the cinema industry in various countries. Distance restrictions and avoiding enclosed spaces result in cinemas not being allowed to operate. Cinema that did not operate during the pandemic caused moviegoers to watch movies online (Palumian et al., 2021). Movie fans subscribe to movies online and access movies according to the wishes of the audience. Many movie fans subscribe to over-the-top (OTT) streaming movies. The application of technology that the wider community has widely used is the internet. Business activities that use the internet make it very easy for buyers and sellers without having to meet each other. Many service providers currently provide internet facilities (Gupta and Singharia, 2021). Digitalization has changed the way people enjoy the entertainment on offer like a tourist (Wen et al. 2020). An increasing number of internet connections, better networks, technological innovations, and the availability of smart devices have resulted in the advent of OTTs offering services to viewers directly over the internet (Gupta \& Singharia, 2021; Godlovitch et al., 2015). OTT in the form of content through the internet is the provision of digital information in the form of writing, sound, images, animation, music, video, movies, games (games), or a combination of some and all, including streaming or downloading by utilizing internet access through telecommunication networks (Putuhena \& Irwansyah, 2019). The streaming platform provides services that provide content and applications over the internet, called OTT services (Shin, Park, \&Lee, 2016). In general, every content needs a good distribution path for customers to enjoy the content. The key to success in distributing content is networking. The increasing fragmentation of the market demands new ways and innovations in distributing content to customers (Putuhena \& Irwansyah, 2019). Movie fans use over-the-top (OTT) streaming to get entertainment in the form of the films. The access to get movies is essential to provide satisfaction to movie fans. OTT services are not transmission networks but services that run over the internet. OTT service providers are generally different from the underlying network operators. This statement shows that OTT represents applications while the provider is a content and application provider company (Putuhena \& Irwansyah, 2019; Godlovitch et al., 2015). The streaming platform users choose movie services at a premium or free subscription. This condition impacts users to be able to use streaming services as needed. The video-on-demand industry experienced a very significant increase during the pandemic. Future developments show the increase in the movie viewers and streaming platforms due to the enactment of lockdown or social restrictions of the community. The pandemic contributes to the increased use of streaming platforms for movie fans who use to watch movies through cinema (Sinclair \& Green, 2015). Other research shows that the development of improved information technology has paved the way for movie fans to access movie platforms in real-time over the internet (Gupta \& Singharia, 2021). The latest digital transformation in digital music technology has been the increasing popularity of streaming platforms that increase customer satisfaction (Sinclair \& Green, 2015). Users in accessing movies using information technology are used and perceived by users of information technology (Tarigan et al., 2020). The want of users to use the streaming platform is controlled by the ministry using the streaming platform and the continued use of the streaming platform. Perceived ease of use, usefulness, and intention to use the streaming platform is a technology acceptance model (TAM) application on the technology (Abdullah et al., 2016). Bassiouni et al. (2019) stated that the adoption of TAM for video game users could produce enjoyment and entertainment. Comfort and ease of use affect the intention of behaving towards video games. Rauniar et al. (2014) stated that the adoption of TAM in business schools in the USA shows that the ease of Facebook users in social networks affects perceived usefulness and intention to use in 389 Facebook users. Giovanis et al. (2012) stated that as many as 212 bank customers familiar with internet use, perceived security, and privacy risk constructs mediate the relationship between compatibility and customer behavior intentions. Therefore, perceived ease of use has an impact on perceived usefulness and customer intention (Abdullah et al., 2016). Kunz et al. (2020) stated that the changing digital era is relevant to the increasing use of technology in sports content consumed through virtual reality technology (VR). Users said sports content and virtual reality could improve behavioral intentions in 570 students educated in Bachelor's, Masters, and Doctoral. surveys conducted electronically to customers can measure professional competence in the learning process for student satisfaction 
(Tarigan et al., 2019). The technology acceptance model (TAM), consisting of perceived ease of use, perceived enjoyment, and perceived usefulness, has an impact on behavioral intention in 368 respondents in the use of internet of things in electronic toll collection (ETC) in China (Gao and Bai, 2014). Research was also conducted by Hubert et al. (2019) on the technology acceptance model (TAM) on smart home applications from 409 respondents in marketing departments at universities in Germany. They found that perceived ease of use has a negative and insignificant effect on behavioral intentions, while perceived usefulness influences behavioral intention. Research conducted by Moghavvemi et al. (2016) stated that entrepreneurs in Malaysia, using information system innovation continuously, could provide work productivity according to the wishes of entrepreneurs to improve business performance. Information technology systems used in restaurants and in hospitality classes in the USA state showed that perceived usefulness, ease of use, and enjoyment could impact behavioral intention (Zhang et al., 2014). Perceived ease of use, perceived usefulness, trust have an impact on the intention to use online platforms through an attitude toward users of the Traveloka website application in Bali in making reservations (Setiawan \& Widanta, 2021). The easy use of cloud computing with ease of use will impact the desire to purchase cloud computing services and willingness to use them to store and access information. Perceived usefulness in cloud computing can increase work efficiency and desire intensively using cloud computing (Ratten, 2014). WeChat payment technology carried out in China shows that the perceived enjoyment influences the intention to use an online platform. It encourages users to use it in the following months (Wu et al., 2017). The results of previous research focused on the technology acceptance model involving perceived ease of use, usefulness, and intention to use. However, very few researchers have used perceived enjoyment and usefulness in online movies. Furthermore, based on the results of previous research, there has been no study of the technology acceptance model (TAM) on moviegoers and streaming platforms in online movies. Therefore, this study has four objectives: First, to find the effects of perceived ease of use on perceived usefulness, intention to use online platforms, and perceived enjoyment in online films. Second, to assess the magnitude of the impact of perceived usefulness on intention to use online platforms and perceived enjoyment. The third investigates the magnitude of the influence of intention to use online platforms on perceived enjoyment and moviegoer behavioral intention. Finally, the fourth is to test the extent of perceived enjoyment on moviegoer behavior.

\section{Literature Review}

Technology Acceptance Model (TAM) is a model for predicting and explaining how technology users accept and use the technology related to one's expectations or desires (Gao \& Bai, 2014). The TAM model aims to explain the behavior of technology users based on belief, intention, and user behavior relationship.

\subsection{Perceived Ease of Use (PEU)}

Perceived ease of use is a level of one's belief that a system can be easily understood. The intensity of use and interaction between users and the system can provide ease of use (Zuniarti et al., 2021). Bassiouni et al. (2019) stated that perceived ease of use is the users' level of effort in using technology such as entertainment in video games. The perceived ease of use is the ease of understanding and interacting with information technology systems used in restaurants (Zhang et al., 2014). Perceived ease of use for Facebook is the ease of understanding, operating, and using it (Rauniar et al., 2014). Perceived ease of use in cloud computing is the ease to use cloud computing, and the more likely it is to adopt these technological innovations (Ratten, 2014). The perceived ease of use, in general, can be said to be the level of confidence a person has that the system can be easily understood, and that it is easy to interact between users in using the smart home systems (Hubert et al., 2019). Bassiouni et al. (2019) measured the perceived ease of using video games as practical, easy to play/use, and easy to understand. Perceived ease of use in hospitality information technology is measured through interacting with the system that does not require significant effort; the system is easy to use and desired (Zhang et al., 2014). Ratten (2014) suggested the indicators in measuring perceived ease of use of cloud computing as easy to use, learn, and operate cloud computing quickly. The use of Facebook as a system for perceived ease of use measured from Facebook is the flexibility in interacting, easiness to access Facebook, easiness to be skilled in the use of Facebook, facebook easy to use, and clear and understandable interaction with Facebook (Rauniar et al., 2014).

\subsection{Perceived Usefulness (PU)}

Perceived usefulness is the level of trust in using a particular subject that can benefit people who use it in services (Zhang et al., 2014; Zuniarti et al., 2021). Perceived usefulness is defined as the degree to which a user believes that using a particular smart speaker system can improve their productivity and job performance (Kowalczuk, 2018). Entrepreneurs in Malaysia use information system innovation that provides skill improvement and can complete tasks (Moghavvemi et al., 2016). Rauniar et al. (2014) define Perceived Usefulness as the degree to which social media users believe that using specific social media sites helps meet the needs of goal-driven individuals. Each social media application offers a specific primary service and offers different tools and apps to add practical value to its audience. Perceived usefulness in cloud computing is related to the desire to access and store information to be implemented on services at universities northeast USA and South China (Ratten, 2014). Perceived usefulness in hospitality information technology classes is measured by the extent the systems can improve performance; systems can increase work productivity, systems can increase work effectiveness, and systems can be useful for easier work (Zhang et al., 2014). The usefulness of Facebook is measured by five indicators: reconnecting with influential people, being helpful in life, being effective in keeping in touch with others, being easy to stay in touch, and being easy to 
stay informed from others (Rauniar et al., 2014). Smart speaker items allow completing tasks faster, smart speakers will improve performance, smart speakers will increase productivity, smart speakers increase device use, and smart speakers make daily life easier (Kowalczuk, 2018). The indicator used by Ratten (2014) in measuring cloud computing in Perceived usefulness is that cloud computing can make everything more efficient, cloud computing can make information storage easier, cloud computing is useful, and cloud computing offers its own advantages. Wu et al. (2017) said that establishing measurement items for perceived usefulness is to allow faster payments, facilitate transactions, increase the efficiency of online transactions, increase productivity, and usefulness for online transactions.

\subsection{Perceived Enjoyment}

Perceived enjoyment is a condition in which an individual uses technology when carrying out his activities and increases his sense of comfort for himself and can also be said to be hedonic in technology for video games (Bassiouni et al., 2019). The higher the level of comfort owned by information technology users, the better the user's attitude that will later be related to the acceptance of the system technology. Feeling happy and comfortable in using information technology systems will make users do their job well and get it done in time (Zhang et al., 2014). The use of technology can provide comfort for users to increase the intensity of technology use in perceived entrepreneurs (Moghavvemi et al., 2016; Kunz et al., 2020). Perceived enjoyment in smart speaker products is defined as the extent to which the use of smart speakers is perceived to please (Kowalczuk, 2018). Bassiouni et al. (2019) measured perceived enjoyment of video games as very entertaining and playing video games with the children was truly enjoyable. Perceived enjoyment in using information technology in restaurants is the happiness of using the system, the process of using the system is pleasurable, and always delighted every time using the system. Measurement items used in using information technology systems in restaurants are set to be the comfortable use of the system; using information systems in restaurants is fun and has fun in using the system (Zhang et al., 2014). The use of smart speakers as Perceived Enjoyment is measured by items in fun using smart speakers, the fun process of using smart speakers, and the pleasure of using smart speakers (Kowalczuk, 2018). Wu et al. (2017) state that perceived emotion as a form of enjoyment for WeChat payment users is measured by some factors showing that using the mobile payment tool is funny, enjoyable, pleasant, and exciting.

\subsection{Intention to use and watch}

Intention to use can be defined as a form of a user's desire to use or reuse a particular object. For example, the intention to use is the desire of entrepreneurs in Malaysia to use information technology to continue improving business performance (Moghavvemi et al., 2016). Interest is one aspect of human psychology that tends to provide further attention or pleasure to the object that can encourage to achieve the goal. For example, the intention is to use information technology, but game users can get and play video games (Bassiouni et al., 2019). Finally, intention reflects the individual's willingness to try to perform a particular behavior. The intention indicates how strongly a person's beliefs try a behavior and how much effort will be used to perform a behavior, such as using Facebook (Rauniar et al., 2014). Bassiouni et al. (2019) measure intention to get and play on video game objects. I frequently get video games, play video games, play video games with my children, and often play video games with my children. The use of Facebook as a system of intensity is called intention to use Facebook with measurement indicators, namely the use of Facebook to communicate with others, to reconnect with influential people and continue to use Facebook for social networking (Rauniar et al., 2014). Ratten (2014) used the measurement item intention to adopt and use cloud computing to purchase cloud computing services and to be willing to use it to store and access information.

\subsection{Behavioral Intention}

Behavioral intention to use is the tendency of behavior to stick with technology. Behavioral intention is a concept to accept or reject technology in using information technology to improve business performance for entrepreneurs (Moghavvemi et al., 2016). Behavioral intentions in information technology systems in hospitality class in the USA are the tendency of restaurant employees to receive and utilize them in work (Zhang et al., 2014). The level of use of smart home technology can be predicted from user attention to the technology. Behavioral intention to use technology is a person's interest (desire) to perform certain behaviors (Hubert et al., 2019). According to Zhang et al. (2014), the indicators of behavioral intentions include restaurantowned systems used continuously, the use of restaurant information technology systems used intensively, and systems in restaurants used for a longer time in the future. The behavioral intention on smart homes is measured with the following items: use of smart home, continuous use of the smart home, and when possible, all time use of the smart home (Hubert et al., 2019).

\subsection{Relationships between Research Concepts}

\subsubsection{Perceived ease of use and perceived usefulness of movies online}

If its users can easily use a service, then automatically, the service can also provide benefits for the user with savings of time and energy. Perceived ease of use positively impacted perceived usefulness in 389 student respondents who used Facebook because of the ease and interaction through Facebook which can be easily understood (Rauniar et al., 2014). Perceived ease of use can be done with electronic surveys to get perceptions from customers, where customers feel comfortable in giving 
opinions (Tarigan et al., 2019). Perceived ease of use of smart home directly influences perceived usefulness due to the ease of using the smart home and the ease of passing it to provide an easier and more profitable life (Hubert et al., 2018). For example, the perceived ease of use has a positive impact on the perceived usefulness of the traveloka website application for users in Bali in making reservations (Setiawan and Widanta, 2021). Perceived ease of use impacts perceived usefulness in using cloud computing in large universities (Ratten, 2014). Finally, perceived ease of use positively influences perceived usefulness in Korean consumer sports and fitness wearable devices (Kim and Ciu, 2019). Based on the relationship between concepts, the first hypothesis can be established, namely:

\section{$\mathbf{H}_{1}$ : Perceived ease of use affects perceived usefulness of movies online.}

\subsubsection{Perceived ease of use affects perceived enjoyment of movies online}

Technology systems can provide convenience, and then automatically, the user will feel comfortable when using the technology (Tarigan et al., 2020). For example, perceived ease of use of smart homes is that it can give enjoyment, where users can get a more comfortable life and increase the comfort of being at home (Hubert et al., 2018). Perceived enjoyment is intrinsic motivation which is a new factor that influences the user to accept a system. For example, perceived ease of use on the use of video games can have an impact on perceived enjoyment due to the ease of play and ease of understanding video games to provide comfort in finding the right video game and finding the right time to play games with family (Bassiouni et al., 2019). A Korean consumer shows that discomfort and insecurity in using sports and fitness wearable devices as a form of negative technology readiness has a negative impact on perceived ease of use, while optimism and innovativeness in the dimension of positive technology readiness have a positive influence on perceived ease of use (Kim \& Ciu, 2019).

H2: Perceived ease of use influences perceived enjoyment of movies online.

\subsubsection{Perceived ease of use affects intention to watch movies online}

The ability of 412 entrepreneurs in Malaysia to use work-related information systems impacts the desire to use them continuously because they can provide skills and capability (Moghavvemi et al., 2016). Perceived ease of use in cloud computing adoption impacted adoption intentions in 135 respondents (Ratten, 2014). The intention to use cloud computing by the students at large universities depends on the ease to use, ease to learn cloud computing, and how to use cloud computing quickly, and it has a direct influence on the desire to buy these services and the desire to access and store data in cloud computing. Perceived ease of use affects the intention to use sports and fitness wearable devices on Korean consumers. The ease of use and interaction is clear and easy to understand in sports and fitness wearable devices has an impact on the desire to use tools regularly and often in the future (Kim and Ciu, 2019). Based on the explanation of the relationship, the second hypothesis can be established:

\section{$\mathbf{H}_{3}:$ Perceived ease of use affects intention to use movies online}

\subsubsection{Perceived usefulness on intention to use movies online}

Entrepreneurs in Malaysia have confidence and believe that the information system impacts their skills and capabilities. Existing information systems are used continuously by 412 entrepreneurs (Moghavvemi et al., 2016). Perceived usefulness in the use of Facebook by students has an impact on intention to use because the use of Facebook increases the effectiveness to stay in touch with others, and it is easier to stay in touch resulting in good communication with others and that encourages them to continuously use Facebook (Rauniar et al., 2014). Perceived usefulness in cloud computing adoption impacted intentions to use on 135 respondents at large universities in the Northeast USA and China (Ratten, 2014). Perceived usefulness positively impacted acceptance intentions in 484 respondents to WeChat's payment system (Wu et al., 2017). Perceived usefulness affects the intention to use sports and fitness wearable devices in Korean consumers because these tools provide a good experience and increase the effectiveness and productivity of tool use, making Korean consumers use the tool regularly and often in the future (Kim \& Ciu, 2019). Based on the explanation of the relationship, a third hypothesis can be established:

\section{H4: Perceived usefulness influences intention to watch movies online.}

\subsubsection{Perceived usefulness and intention to use on perceived enjoyment of movies online}

A technology system that provides many benefits will be more comfortable for users who use the technology (Palumian et al., 2021). Perceived usefulness in the use of video games with good image and subjective form and social interaction can result in discomfort and insecurity impact in using sports and fitness wearable devices as a form of negative technology readiness to have a negative effect on perceived usefulness (Kim and Ciu, 2019). The information system used by entrepreneurs in Malaysia has as many as 412 respondents with a male gender 305 (74.3\%), and Women 107 respondents (25.7\%) continuously provide comfort for them because they can improve skills and competence (Moghavvemi et al., 2016). Korean 
consumers show that discomfort and insecurity in using sports and fitness wearable devices as a form of negative technology readiness negatively impact intention to use through perceived ease of use and perceived usefulness (Kim and Ciu, 2019).

Hs: Perceived usefulness affects perceived enjoyment of watching movies online.

$\mathbf{H}_{6}$ : Perceived enjoyment influences the intention to use watching movies online.

\subsubsection{Intention to use online platforms affecting behavioral intention of watching film online}

The information system is used continuously by entrepreneurs in Malaysia as many as 412 respondents according to cold expectations because it can provide business improvement for entrepreneurs (Moghavvemi et al., 2016). Restaurant employees in using information systems in hospitality class in the USA can impact behavioral intention by using independent variable power and gender (Zhang et al., 2014). The use of Facebook by students can enable them to intensively communicate with others, to reconnect with other people, and continuously use Facebook to impact behavioral intention in the actual use of Facebook (Rauniar et al., 2014). Restaurant employees' convenience of users of information technology systems in hospitality classes in the USA can impact behavioral intentions because employees are increasingly inclined to using the system (Zhang et al., 2014). Perceived emotions set by using the mobile payment tool are funny, pleasant, exciting, and enjoyable, which have a positive impact on acceptance intentions on the use of WeChat payment (Wu et al., 2017). Comfort for users when using a smart home affects behavioral intentions because the smart home provides increased convenience to provide a situation to use smart home access continuously and use the smart home at any time as needed (Hubert et al., 2019). The ability to get video games that can be entertaining and the right timing to play video games with the family can provide the correct behavioral intention to get and play video games (Bassiouni et al., 2019).

$\mathbf{H}_{7}$ : Intention to use affects moviegoer behavioral intention of watching movies online.

H8: Perceived enjoyment affects moviegoer behavioral intention of watching movies online.

Based on the argument in the introduction, literature review, and the relationship between concepts in research, the research model describing the relationship between constructs and corresponding hypotheses is depicted in Fig. 1.

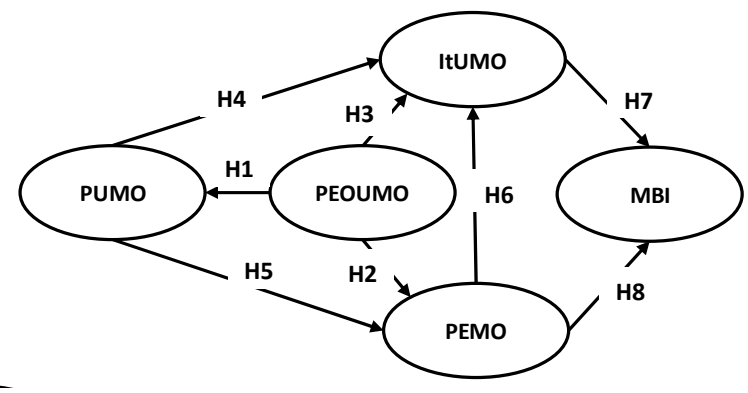

Fig. 1. Research Framework and Hypotheses

\section{Research Methods}

This study is a causal relationship research that tests the influence between constructs as described in Fig. 1. The population in this study is the moviegoers subscribing to moviegoers streaming platforms during the pandemic era. Researchers distributed questionnaires through WhatsApp groups, Facebook, and Instagram by sending google form links. The questionnaire is prepared and designed based on the previous studies. Researchers assigned measurement items for each construct. The first construct, perceived ease of use, used four items, i.e., ease to play movies online, ease to understand, ease to interact using online movies, and ease to understand (Bassiouni et al., 2019; Zhang et al., 2014; Ratten, 2014; Rauniar et al., 2014). The second variable, the perceived usefulness of movies online, has four items: online movies increase the effectiveness in getting entertainment, online movies increase the efficiency of entertainment, online movies make it easy to stay informed, and online movies are obtained in a short time in real-time (Zhang et al., 2014; Rauniar et al., 2014; Kowalczuk, 2018; Ratten, 2014; Wu et al., 2017). Furthermore, the intention to use movies online adopts measurement by Bassiouni et al. research. (2019), namely, frequently to get movies online, watching movies online, frequently watching movies online with family, and spending a long time watching with family. The fourth variable is perceived enjoyment set with measurement items: using online movies, using movies online is fun, always delighted every time watching a movie online, and emotions are stable when watching movies online (Kowalczuk, 2018; Zhang et al., 2014; Wu et al., 2017). Finally, moviegoers' behavioral intention as the fifth variable is measured by adopting Hubert et al. research (2019) that is to have access to movies online will use it, use online movies continuously, and when possible, always use online movies (Hubert et al., 2019). The questionnaires are distributed by sharing the Google Form links due to enacting restrictions on community activities. The result of data collection provides seven hundred eighty (780) respondents who completed the questionnaires, but 772 responses are eligible for further analysis processed using partial least squares (PLS). 


\section{Results}

Based on the collected data, the respondent profile consists of men 378 (49\%) and women 394 (51\%). The respondents live in East Java 472 respondents, Ambon and Papua 15 respondents, Bali and Nusa Tenggara 43 respondents, Kalimantan 90 respondents, Sumatra 10 respondents, Central Java and Yogyakarta 87 respondents, West Java and DKI Jakarta 10 respondents, and Sulawesi 45 respondents. Characteristics of respondents based on the streaming platforms subscriber and the frequency of watching per week less than two times amounted to 4 respondents, three to five times a week amounted to 54 respondents, six t to 8 times a week eight respondents, nine to 12 times a week 28 respondents, and more than 17 times a week amounted to 678 respondents. Thus, moviegoers watch online movies for 1-1.5 hours per week on average during the pandemic. During the pandemic, the number of subscribers for streaming platforms increased by 13 million subscribers (26.5\%) in 2020, especially after the Indonesian government stated large-scale social restrictions or limited lockdown (lipi.press, 2021). The growth in the number of subscribers to platform streaming shows that people in Indonesia already rely on movies through streaming platforms rather than watching movies at the nearest cinema because of concerns about closed rooms and contracting Covid 19. Model testing used partial least square tools to test the outer loading and inner model. The outer loading test consisting of a validity test, reliability test, and AVE test is shown in Table 1. The inner model test is shown by Q-square calculations (Table 2), path coefficient (Table 3), and hypothesis tests.

\section{Table 1}

Validity and reliability of the measurement result

\begin{tabular}{|c|c|c|c|c|}
\hline Construct and Item & Loading & Comp. & Cronb. & AVE \\
\hline \multicolumn{2}{|l|}{ Perceived ease of use of movie online (PEoUMO): } & \multirow{5}{*}{0.823} & \multirow{5}{*}{0.716} & \multirow{5}{*}{0.538} \\
\hline Easy to play movies online (PEoUMO1) & 0.761 & & & \\
\hline Easy to understand movies online. (PEoUMO2) & 0.778 & & & \\
\hline Easy to interact using movies online. (PEoUMO3) & 0.638 & & & \\
\hline You can quickly use movies online. (PEoUMO4) & 0.749 & & & \\
\hline \multicolumn{2}{|l|}{ Perceived usefulness of movies online (PUMO): } & \multirow{5}{*}{0.833} & \multirow{5}{*}{0.755} & \multirow{5}{*}{0.569} \\
\hline Movies online increase the effectiveness of getting entertainment (PUMO1) & 0.533 & & & \\
\hline Online movies increase efficiency in getting entertainment (PUMO2) & 0.891 & & & \\
\hline Movies online make it easy to stay informed about the latest movies (PUMO3) & 0.592 & & & \\
\hline Movies online are available in real-time. (PUMO4) & 0.919 & & & \\
\hline \multicolumn{2}{|l|}{ Intention to use movies online (ItUMO): } & \multirow{5}{*}{0.842} & \multirow{5}{*}{0.751} & \multirow{5}{*}{0.576} \\
\hline Frequently get movies online. (ItUMO1) & 0.82 & & & \\
\hline Watching movies online. (ItUMO2) & 0.594 & & & \\
\hline Frequently watching movies online with my family. (ItUMO3) & 0.716 & & & \\
\hline Spend a long time watching with family (ItUMO4) & 0.875 & & & \\
\hline \multicolumn{2}{|l|}{ Perceived enjoyment (PEMO): } & \multirow{5}{*}{0.844} & \multirow{5}{*}{0.757} & \multirow{5}{*}{0.578} \\
\hline It's nice to use movies online. (PEMO1) & 0.609 & & & \\
\hline Watching using movies online is very fun. (PEMO1) & 0.736 & & & \\
\hline Feeling happy every watching movie online (PEMO1) & 0.836 & & & \\
\hline Emotions are stable watching movies online (PEMO1) & 0.836 & & & \\
\hline \multicolumn{2}{|l|}{ Moviegoer behavioral intention (MBI) } & \multirow{4}{*}{0.875} & \multirow{4}{*}{0.788} & \multirow{4}{*}{0.702} \\
\hline Have access to movies online; then I will use them (MBI1) & 0.881 & & & \\
\hline Use movies online continuously (MBI2) & 0.924 & & & \\
\hline When possible, use online movies at any time (MBI3) & 0.691 & & & \\
\hline
\end{tabular}

Table 1 demonstrated the test result of factor loading and reliability. The result indicated that all factor loading of the indicator exceeds the value 0.50 as the minimum recommended acceptable value. Hence, the convergent validity requirement for all indicators is met. Besides the convergent validity, discriminant validity needs to be assessed by looking at the Forner and Larcker criterion. The finding of the analysis indicated that all square roots of the AVE value of each construct is greater than the correlation value between constructs. Therefore, the discriminant validity requirement is fulfilled, and those indicators are considered valid. The reliability of the measurement model is assessed by looking at the value of composite reliability (C/R), Cronbach Alpha (C/A), and average variance extracted (AVE). The recommended value of composite reliability and Cronbach Alpha is 0.70 , and 0.50 for the AVE value. In Table 2, all values of C/R and C/A are greater than 0.70, and AVE value is also greater than 0.50 . Therefore, all indicators are considered reliable. Besides, the analysis is to assess the inner model for R2 and Q2 as a goodness of fit testing. The value of R2 indicates the extent to which the exogenous variable explains the variance of the endogenous variable. Based on the result of the analysis, it is found that the $\mathrm{R} 2$ for behavioral intention is 0.482 , which means that the variance of behavioral intention is explained by the other four variables up to $48.20 \%$, while the rest of the variance corresponds to other variables. This R2 value is categorized as a moderate value and acceptable. Moreover, another assessment is to seek the predictive relevance of the research model, which is reflected by the Q2 value, which is greater than zero for an excellent predictive relevance. The result indicated that the Q2 value of the model is 0.076 . Hence, the model has good predictive relevance. Furthermore, the analysis is to examine the hypotheses by looking at the patch coefficient and $\mathrm{t}-$ value. Table 2 and Fig. 2 demonstrated the research model and corresponding analysis results on the outer and inner models. As shown, all patch coefficients have a positive value with the t-value exceeding 1.96 as the minimum acceptable value for the significant level of 5\%. This finding shows that all eight hypotheses are supported in this study. The first hypothesis (H1) that perceived ease of use positively affects the perceived usefulness of watching movies online is supported with a coefficient of 0.434 and a t-value of $11.942>1.96$. The second hypothesis(H2), perceived ease of use affects perceived enjoyment of 
watching movies online, is also supported with a coefficient of 0.198 and a t-value of $4.368>1.96$. Furthermore, the third hypothesis(H3), that perceived ease of use has a positive and significant effect on the intention to use watch movies online, is supported with the coefficient of 0.618 and t-value of $22.471>1.96$.

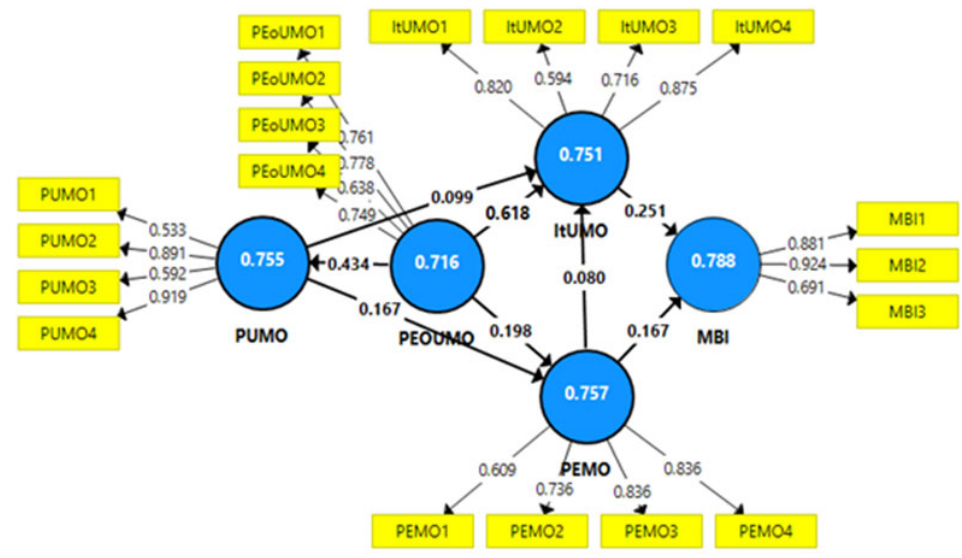

Fig. 2. Research Model and Result

Likewise, the result supported the fourth hypothesis, that perceived usefulness positively affects the intention to watch movies online with a coefficient of 0.099 and t-value of $2.834>1.96$. Moreover, the results also indicate the fifth hypothesis (H5), that perceived usefulness influences the perceived enjoyment of watching movies online, with the coefficient of 0.167 and $t-$ value of $3.208>1.96$. In addition, the sixth hypothesis (H6) is found to support that perceived enjoyment affects intention to use with the coefficient of 0.080 and t-value of $2.683>1.96$. Besides, the result also indicated that intention to use impacts the behavioral intention with the coefficient of 0.251 and $t$-value of $5.905>1.96$. Finally, the last hypothesis stating the perceived enjoyment influences the behavioral intention is supported with the coefficient of 0.167 and t-value of $230>1.96$.

Table 2

Hypothesis and Path Coefficient

\begin{tabular}{|c|c|c|c|}
\hline Relationship & Path Coefficient & T Statistics & Remarks \\
\hline PEOUMO $\rightarrow$ PUMO (H1) & 0.434 & 11.942 & supported \\
\hline PEOUMO $\rightarrow$ PEMO (H2) & 0.198 & 4.368 & supported \\
\hline PEOUMO $\rightarrow$ ItUMO (H3) & 0.618 & 22.471 & supported \\
\hline $\mathrm{PUMO} \rightarrow$ ItUMO $(\mathrm{H} 4)$ & 0.099 & 2.834 & supported \\
\hline PUMO $\rightarrow$ PEMO (H5) & 0.167 & 3.208 & supported \\
\hline PEMO $\rightarrow$ ItUMO (H6) & 0.080 & 2.683 & supported \\
\hline ItUMO $\rightarrow$ MBI (H7) & 0.251 & 5.905 & supported \\
\hline $\mathrm{PEMO} \rightarrow \mathrm{MBI}(\mathrm{H} 8)$ & 0.167 & 4.230 & supported \\
\hline
\end{tabular}

\section{Discussion}

Data processing results indicate that perceived ease of use positively affects the perceived usefulness of online movies. This correlation shows that the perceived ease of use shown in easy to watch movies online and understand movies online make online movie audiences increase the efficiency in getting entertainment and make it easier to stay informed about the latest online movies. This study supports the study results, which states that perceived ease of use is positively correlated with perceived usefulness of movies online (Moghavvemi et al., 2016; Bassiouni et al., 2019; Rauniar et al., 2014; Bassiouni et al., 2019; Ratten, 2014; Zuniarti et al., 2021; Tarigan et al., 2020). Furthermore, perceived ease of use to perceived enjoyment of movies online is obtained positively and significantly correlated. This correlation shows that easy-to-understand movies online and can quickly watch online movies determine the audience in watching online movies and the process of online movie watching is enjoyable for the audience. This study supports the results of research that states that perceived ease of use impacts perceived enjoyment of movies online (Hubert et al., 2018; Bassiouni et al., 2019; Kim and Ciu, 2019). The results also showed that perceived ease of use had a positive and significant effect on the intention to use and watch movies online. The results of this influence are obtained from the ease to interact using online movies and quickly using online movies online streaming platforms that enable the movie fans to get movies online and to watch movies online on a regular basis. This study supports the research results that state that perceived ease of use has a positive and significant effect on the intention to use and watch movies online (Moghavvemi et al., 2016; Ratten, 2014; Kim and Ciu, 2019). In addition, the results of the hypothesis also showed that perceived usefulness correlated with intention to use movies online positively and significantly. Therefore, this correlation obtained by movies online increases the efficiency in getting entertainment and makes it easier to stay informed about the latest movies and can determine frequently getting movies online and watching movies online for viewers continuously. The results of this study show that the usefulness of the audience in an efficient and fast way in using the 
streaming platform to get something useful and make the audience feel entertained or enjoy the available movies will impact increasing the frequency of use. Therefore, this study supports the research results that states that perceived usefulness influences the increase in intention to use movies online (Moghavvemi et al., 2016; Rauniar et al., 2014; Ratten, 2014; Wu et al., 2017; Kim and Ciu, 2019). Other results also showed that perceived usefulness had a positive and significant increase in perceived enjoyment of movies online. The influence of variable perceived usefulness determined by frequently watching movies online with my family and using a long time watching with the family has an influence on using online movies and I am always happy every time I watch movies online. The results of this study are in line with the study results, which states that perceived usefulness affects increasing perceived enjoyment (Kim \& Ciu, 2019; Moghavvemi et al., 2016). The next hypothesis is that intention to use has a positive and significant effect on perceived enjoyment of movies online. This correlation shows that intention to frequently watch movies online with my family and spending a long time watching with family can provide perceived enjoyment. Online moviegoers are happy and able to enjoy movies that are with the family. Online moviegoers can tell stories to each other while watching films, building togetherness, and exchanging ideas and thoughts. This study supports the research results that state that intention to use affects perceived enjoyment of movies online (Kim and Ciu, 2019; Moghavvemi et al., 2016). Intention to use impacts the increase in moviegoer behavior intention of movies online. The positive influence is caused by frequently getting movies online and watching movies online, impacting moviegoers always to use online movie access continuously, and when there is an opportunity to always use online movies. This study confirms the research results that the intention to use affects the increase in moviegoer behavior intention (Moghavvemi et al., 2016; Zhang et al., 2014; Rauniar et al., 2014; Giovanis et al., 2012). Perceived enjoyment obtained by the audience can positively influence moviegoer behavior and intention of movies online significantly. Perceived enjoyment such as very enjoyable, always happy every watching movies online and emotion stable when watching movies online makes moviegoers always use online movie access continuously. The audience's pleasure when using online movies will provide conditions to the audience always using online movies when they have the opportunity.

The results of this study have implications for practitioners in the industry and business. This finding shifts the marketing strategy of products that have been directly aired in cinemas that are enjoyed directly by the audience. Covid conditions result in changes in maintaining the distance with fellow communities and in avoiding closed rooms with large numbers of people to prevent the spread of covid-19. The rapid development of internet technology allows the film industry to use streaming platforms to be easily enjoyed by a broad audience. Users streaming in real-time can instantly enjoy the movie anytime, anywhere, and the family can enjoy the movie. Movies on streaming platforms can be played repeatedly at an affordable cost. The research implications are theoretically able to enrich the theory of the technology acceptance model in online movies. Currently, there will be a new normal condition for the public to enjoy and use movies continuously online through the internet access.

\section{Conclusion}

This study investigates the extended application of the technology model acceptance (TAM) by including the constructs of perceived ease of use, perceived usefulness, enjoyment, and intention to use on the behavioral intention on the streaming cinema platforms. The results showed the extended application of TAM on streaming cinema platforms. Perceived ease of use positively affects perceived usefulness, enjoyment, and intention to use. Furthermore, perceived usefulness influences the perceived enjoyment and intention to use. Perceived enjoyment affects intention to use and behavioral intention. Finally, intention to use affects behavioral intention. The results also indicated that perceived ease of use indirectly affects behavioral intention through perceived enjoyment and intention to use. This result provides insight for movie industry practitioners on how to improve the customers' behavioral intentions. Besides, this study contributes to the current research in the application of TAM in digital streaming cinema platforms.

\section{Acknowledgement}

This research is funded by the government Indonesia with PDUPT (Penelitian Dasar Unggulan Perguruan Tinggi) project number 001/AMD-SP2H/LT-MULTI-PDPK/LL7/2021

\section{References}

Abdullah, F., Ward, R., \& Ahmed, E. (2016). Investigating the influence of the most commonly used external variables of TAM on students' perceived ease of use (PEOU) and perceived usefulness (PU) of e-portfolios. Computers in Human Behavior, 63, 7590.

Bassiouni, D.H.B., Hackley, C., \& Meshreki, H. (2019). The integration of video games in family-life dynamics: An adapted technology acceptance model of family intention to consume video games. Information Technology \& People, 32(6), 1376-1396, DOI 10.1108/ITP-11-2017-0375.

Ehrlich, J.A., Ghimire, S., Khraiche, M., \& Raza, M.F. (2020). COVID-19 countermeasures, sporting events, and the financial impacts to the North American leagues. Managerial Finance, 47(6). 0307-4358, DOI 10.1108/MF-05-2020-0275

Gao, L., \& Bai, X. (2014). A unified perspective on the factors influencing consumer acceptance of internet of things technology. Asia Pacific Journal of Marketing and Logistics, 26(2), 211-231. https://doi.org/10.1108/APJML-06-2013-0061 
Ghosh, J. (2020). A critique of the Indian government's response to the COVID-19 pandemic. Journal of Industrial and Business Economics, 47, 519-530

Giovanis, A.N., Binioris, S., \& Polychronopoulos, G. (2012). An extension of TAM model with IDT and security/privacy risk in the adoption of internet banking services in Greece. EuroMed Journal of Business, 7(1), 24-53.

Godlovitch, I., Kooterink, B., Marcus, J. S., Nooren, P., Esmeijer, J., \& Roosendaal, A. (2015). Over-the-Top (OTTs). Policy Department A: Economic and Scientific Policy. https://doi.org/10.2861/706687

Gupta, G., \& Singharia, K. (2021). Consumption of OTT Media Streaming in COVID-19 Lockdown Insights from PLS Analysis. Vision, 25(1), 36-46, DOI: 10.1177/0972262921989118

Hubert, M., Blut, M., Christian, B., Zhang, R.W., Koch, V., \& Riedl, R. (2019). The influence of acceptance and adoption drivers on smart home usage. European Journal of Marketing, 53(6), 1073-1098, DOI 10.1108/EJM-12-2016-0794

Kim, T., \& Chiu, W. (2019). Consumer acceptance of sports wearable technology: the role of technology readiness. International Journal of Sports Marketing and Sponsorship, 20(1), 109-126. https://doi.org/10.1108/IJSMS-06-2017-0050

Kunz, R. E., \& Santomier, J. P. (2020). Sport content and virtual reality technology acceptance. Sport, Business and Management, Bingley 10(1), 83-103. DOI:10.1108/SBM-11-2018-0095

Kowalczuk, P. (2018). Consumer acceptance of smart speakers: a mixed methods approach. Journal of Research in Interactive Marketing, 12(4), 418-431. https://doi.org/10.1108/JRIM-01-2018-0022

Lipi.Press. (2021). Sirkulasi Film Platform Streaming di Indonesia. https://lipipress.lipi.go.id/detailpost/sirkulasi-film-platformstreaming-di-indonesia

Moghavvemi, S., Salleh, N.A.M., \& Standing, C. (2016). Entrepreneurs adoption of information system innovation: The impact of individual perception and exogenous factors on entrepreneurs behavior. Internet Research, 26(5), 1181-1208, DOI 10.1108/IntR01-2014-0024

Ozili, P. (2020). COVID-19 in Africa: socio-economic impact, policy response and opportunities. International Journal of Sociology and Social Policy. https://doi.org/10.1108/IJSSP-05-2020-0171

Palumian, Y., Jayanti, S.C.K., Indriyani, R., \& Tarigan, Z.J.H.T. (2021). Technology acceptance model for online cinema ticketing among moviegoers in java island Indonesia: an empirical study on tix id application. IOP Conf. Series: Materials Science and Engineering, 1010, 012037, doi:10.1088/1757-899X/1010/1/012037

Putuhena, A.G., \& Irwansyah, (2019). The role of over-the-top (OTT) services in illegal music consumer. Jurnal Studi Komunikasi Dan Media, 23(2), 167-180.

Ratten, V. (2014). A US-China comparative study of cloud computing adoption behavior: The role of consumer innovativeness, performance expectations and social influence. Journal of Entrepreneurship in Emerging Economies, 6(1), 53-71.

Rauniar, R., Rawski, G., Yang, J., \& Johnson, B. (2014). Technology acceptance model (TAM) and social media usage: an empirical study on Facebook. Journal of Enterprise Information Management, 27(1), 6-30.

Setiawan, P.Y., \& Widanta, A.B.P. (2021). The effect of trust on travel agent online use: Application of the technology acceptance model. International Journal of Data and Network Science, 5(3), 173-182, DOI: 10.5267/j.ijdns.2021.6.015

Shin, J., Park, Y., \& Lee, D. (2016). Strategic management of over-the-top services: Focusing on Korean consumer adoption behavior. Technological Forecasting and Social Change, 112, 329-337. https://doi.org/10.1016/j.techfore.2016.08.004

Sinclair, G., \& Green, T. (2015). Download or stream? Steal or buy? Developing a typology of today's music consumer. Journal of Consumer Behaviour, 15, 3-14. https://doi.org/10.1002/cb

Tarigan, Z.J.H., Sutapa, I.N., Mochtar, J., \& Suprapto, W. (2019). Measuring teachers' competency in determining students' satisfaction through electronic internet survey method. International Journal of Information and Education Technology, 9(3), 236240, doi: 10.18178/ijiet.2019.9.3.1206

Tarigan, Z.J.H., Basuki, R., \& Siagian, H. (2020). The impact of information technology quality on electronic customer satisfaction in movie industry. International Journal of Data and Network Science, 4(3), 263-270

Verity, R., Okell, L.C., Dorigatti, I., Winskill, P., Whittaker, C., \& Imai, N. (2020) Estimates of the severity of coronavirus disease 2019: a model-based analysis. The Lancet Infectious Diseases, 20(6), 669-677.

Wen, J., Kozak, M., Yang, S., \& Liu, F. (2020). COVID-19: potential effects on Chinese citizens' lifestyle and travel. Tourism Review, 76(1), 74-87,

Wu, J., Liu, L., \& Huang, L. (2017). Consumer acceptance of mobile payment across time: Antecedents and moderating role of diffusion stages. Industrial Management \& Data Systems, 117(8), 1761-1776, DOI 10.1108/IMDS-08-2016-0312

Yu, X., Liu, C., Wang, H., \& Feil, J.-H. (2020). The impact of COVID-19 on food prices in China: evidence of four major food products from Beijing, Shandong and Hubei Provinces. China Agricultural Economic Review, 1756-137X, DOI 10.1108/CAER04-2020-0054

Zhang, H. (2020). China's employment stabilization policies in response to the impact of the COVID-19 pandemic. International Journal of Sociology and Social Policy, 0144-333X, DOI 10.1108/IJSSP-05-2020-0167

Zhang, L., Nyheim, P., and Mattila, A.S. (2014). The effect of power and gender on technology acceptance. Journal of Hospitality and Tourism Technology, 5(3), 299-314, DOI 10.1108/JHTT-03-2014-0008

Zuniarti, I., Yuniasih, I., Martana, I.K., Setyaningsih, E.D., Susilowati, I.H., Pramularso, E.Y., \& Astuti, D. (2021). The effect of the presence of e-commerce on consumer purchasing decisions. International Journal of Data and Network Science, 5 (3), 479 484, DOI: $10.5267 / j . i j d n s .2021 .3 .005$

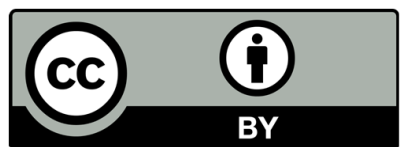

(C) 2022 by the authors; licensee Growing Science, Canada. This is an open access article distributed under the terms and conditions of the Creative Commons Attribution (CC-BY) license (http://creativecommons.org/licenses/by/4.0/). 